\title{
Running Like Alice and Losing Good Ideas: On the Quasi-Compulsive Use of English by Non-native English Speaking Scientists
}

\author{
Alejandro Bortolus
}

Received: 18 January 2012/Revised: 29 March 2012/Accepted: 12 April 2012/Published online: 7 September 2012

This synopsis was not peer reviewed.

\section{INTRODUCTION: THE OVERLOOKED OUTCOME OF AN OLD PROBLEM}

The profuse publication of articles and books debating the use and abuse of English as a global language for science (Garfield 1962; Amonn 2001; Montgomery 2004) evidences the timeless persistence of a complex and unsolved problem with deep multi-cultural roots. Many non-native English speaking (hereafter, non-NES) countries currently exert enormous explicit or implicit pressure on their scientists to publish in international high-impact peerreviewed journals, which are in English. This pressure is promoted under the premise that the impact factor of a journal is positively related to the quality of the science it publishes. This premise implies that publishing in highimpact peer-reviewed journals is the best way to demonstrate the excellence of local scientists. Whether we agree with this premise or not, and independently of its legitimacy (Clavero 2010a, b; Guariguata et al. 2010), we have long accepted it as the paradigmatic scenario that rules the way we do science and publish scientific results worldwide. Indeed, "this is the way it is", as Gannon (2008) wrote in a singular editorial for the prestigious journal EMBOReports. In Argentina, for instance, the National Council for Scientific and Technologic Research evaluates a researcher's professional performance with a system that assigns decreasing scores to papers in the first, second, and third portions of a list of international journals with decreasing impact factors. Below the third portion of that list, the system places papers published in local journals, usually with no impact factor. Consequently, most of our researchers do anything in their power to publish their papers in journals in the first and second thirds of the list, indirectly withdrawing their support from local editorials and journals (including manuscript submissions and valuable editorial assistance). Hence, the aim of publishing papers in high-impact peer-reviewed journals eventually leads non-NES scientists to almost exclusively produce papers in English, leading to a self-perpetuating cycle in which English becomes an increasingly important and ineludible tool to communicate scientific findings (Tardy 2004). In this article, I propose that the ultimate problem in this scenario is that the obligation to write exclusively in English is progressively deteriorating non-NES schools of thought, the quality of interactions between scientists and people and between advisors and advisees, and the integrity of local natural resources and biodiversity. Furthermore, this obligation hinders the emergence of many potentially brilliant minds.

\section{ERODING THE VIGOR AND QUALITY OF NON-NES SCHOOLS OF THOUGHT: THE ALICE EFFECT}

The most eloquent thinkers, speakers, and writers can spoil the communication of their best ideas by using a second language. It is a mistake to think that presenting your findings in a logical and attractive fashion is independent of language (La Madeleine 2007). In fact, many non-NES scientists do not write exactly what they want to say (meaning what they would have written in their first language); instead, they write the best they can write in 
English about what they want to say. If a scientist does not master English, writing a manuscript becomes an exhausting, extensive process. Copying elegant phrases and expressions from the literature (within the legal bounds) may help to improve style and clarity, but it often results in awkward semantic collages or nonsense that forces the writer to restart paragraphs or even the entire manuscript. To avoid these problems, non-NES scientists try to ensure that their manuscripts are reviewed by relatively expensive expert translators and/or colleagues. After passing this first idiomatic review, the manuscript is submitted to an international journal, where it begins the regular peer review process. The entire process normally takes at least two or three times longer than writing in the non-NES's first language. Furthermore, arguing and debating on a criticized critical paper often takes longer than editors expect because of the extra time needed to carefully select the most accurate expressions. Indeed, non-NES scientists face a constant trade-off between hastening the writing process to increase their publication rate and taking the appropriate time to maximize the clarity of their ideas. Additionally, a non-NES scientist continually uses a considerable proportion of his/her working time to study English and to solve linguistic problems instead of scientific ones. The number of native English speaking (hereafter NES) colleagues and friends willing to help with these difficult linguistic tasks decreases over time and may result in the progressive isolation of the non-NES scientist. Indeed, for many people at this difficult stage, trading linguistic assistance for authorship may be the crucial action that will determine whether to publish or perish. Ultimately, the number of articles and ideas published per year is considerably lower than if these articles were written in the non-NES's first language. Non-NES scientists feel like Alice being lectured by the Red Queen: "It takes all the running you can do, to keep in the same place" (in terms of academic publishing advances). "If you want to get somewhere else" (e.g., increase the publication rate over time), "you must run at least twice as fast as that". Unfortunately, going faster is an impossible task for a non-NES scientist because linguistic and scientific skills always compete with each other for a limited, and constantly decreasing, amount of time.

\section{PREVENTING NON-NES SCIENTISTS FROM ACHIEVING HIGH STANDARDS OF EXCELLENCE AND RECOGNITION}

NES editors often become understandably discouraged by the low performance exhibited by non-NES experts expressing themselves in English (Meneghini and Packer 2007; Gannon 2008). Editing of non-NES scientists' texts takes considerably longer and is more time consuming than texts authored by trained NES scientists. The result is a relatively slower publication rate as well as low participation of non-NES scientists in scientific books and reviews edited by their NES peers, even within their fields of expertise and geographic area (Tardy 2004). As a result, non-NES researchers, young scientists, and students commonly buy and learn from books authored by NES scientists, in which the discussion of ideas proposed by local nonNES researchers is poor or non-existent. In this context, many young non-NES scientists see collaboration with NES researchers (e.g., participating in ongoing research and engaging in graduate programs) as the ultimate means of achieving academic excellence and/or increasing their publication success (Tardy 2004), disregarding, ignoring or avoiding direct contact with local specialized research teams and the schools of thought they create and promote. Additionally, young non-NES scientists with a poor command of English tend to avoid graduate programs that have an obvious preference for candidates with good English skills. The overall result is a sustained local brain drain with negative impacts on the diversity of original ideas debated by the local and international scientific communities.

\section{THREATENING LOCAL NATURAL RESOURCES AND BIODIVERSITY OF NON-NES COUNTRIES}

The exclusive production of papers in English is likely to delay the transmission of key information within and among non-NES nations. It has been noticed, for instance, that medical doctors in non-NES countries often suffer significant delays in the acquisition of valuable new information due to idiomatic problems (Meneghini and Packer 2007). The same situation occurs among those guarding the natural resources and biodiversity in non-NES countries. A good example comes from my own field. Most of my fellow ecologists share the reality that our discoveries and ideas about biodiversity, natural history and ecology are ignored by most (though not all) local environmental managers and park rangers who, for a variety of understandable reasons, usually have a poor command of the English language. Even when non-NES circulate their papers in English in local natural resource offices and nongovernmental organizations, they often receive faster feedback from foreign colleagues than from locals. Attending national scientific meetings does not help them much in this situation because non-NES researchers prefer international conferences (where English is the working language) over national ones to perform better on their institutional examinations. Ironically, references to works by non-NES authors published in their native languages are often considered gray literature, and their citation is commonly discouraged by editors of international 
peer-reviewed journals published in English. Consequently, the impact of non-English works tends to fade away rapidly. Although local environmental managers and rangers are eager to learn about local systems to make accurate managing decisions to protect natural resources, a linguistic short circuit prevents that from happening efficiently.

As Robert Winston highlighted in his Scientist's Manifesto, "We need to strive for clarity not only when we make statements or publish work for scientific colleagues, but also in making our work intelligible to the average layperson" (Winston 2010). Of course, Winston knows that, especially in developed countries like his, many professionals act as intermediary communicators between scientists and laypeople, including naturalists, journalists, and the staff of a variety of governmental and nongovernmental organizations, among others. Nevertheless, scientists must address this moral dilemma as a matter of good citizenship (Rotblat 1999; Halliday 2009), especially in regions where good intermediary communicators are rare or absent and where English is not the local language.

\section{CONCLUDING REMARKS}

The compulsive use of English does not necessarily help to improve the creation, communication, and exchange of original and useful scientific ideas. Why do non-NES scientists continue to attempt to publish almost exclusively in English? Some are still convinced that this is the best way to do it (e.g., Agudelo 2010) but other alternative explanations still deserve the thorough attention of specialists. I agree with the idea of a Nash equilibrium that defines this as a multi-party, non-collaborative game (Bergstrom and Bergstrom 2006). Considering the benefits of publishing in English (see first paragraph), no one has anything to gain by changing only her/his individual strategy unilaterally and it is highly unlikely that all non-NES will coordinate to shift journals simultaneously. Nevertheless, we could help improving this situation by finding and articulating partial but complementary solutions.

To optimize our attempt to solve this problem, we must first stress the fact that this is not about stopping publishing in English, for there is a genuine need to do so (Tardy 2004). We need a working language to communicate and exchange ideas with colleagues worldwide, and English is the language we presently use. Non-NES scientists must receive English training to publish their ideas and also to collaborate actively with the international scientific community by integrating advisory boards and committees. Second, this issue is not really about a competition between non-NES and NES scientists (see Clavero 2010a, b) because this game will be lost or won together by losing or gaining diversity of ideas, perspectives, hypotheses, and solutions. Non-NES scientists only follow national and international (often self-inflicted) regulations that are conceived with the implicit purpose of proving the excellence of local science. However, we must keep in mind that the quality of the science produced by a society does not depend on the few papers published in top journals by a few of its scientists but on the quantity and quality of the ideas developed and debated over time by the largest possible number of scientists. Thus, I suggest the following. (1) non-NES scientists must exercise their legitimate right to write and communicate their ideas in their own language without negative feedback. (2) International scientific editorials should help non-NES scientists to counteract the loss of valuable local literature, historically considered disposable gray literature, by encouraging their citation and soliciting (through the "Guide for Authors") electronic reprints to archive them as supporting material with open access (a win-win situation). (3) Local non-NES scientific institutions and editorials should support more, and explicitly, the publication of books and review papers in local languages to make this information more accessible to laypeople and to promote the engagement of young non-NES scientists in modern local schools of thought. (4) Leading non-NES scientific journals and editorials must pursue the creation of experienced and attractive editorial boards willing to achieve the highest possible standard of publication based on international counterparts. There is no point in favoring publication in local languages if the quality of the resulting papers will be mediocre. (5) Balancing the number of publications in English with those in local languages must be on the agenda of all non-NES nations that aim to achieve the sustainable development of local science in communion with society. Every nonNES nation must determine its own optimal balance by considering local socio-economic and cultural needs. By achieving an appropriate balance between English and non-English publications, democratic socially progressive governments can enhance not only the interaction between non-NES scientists and their societies but also the scientific debates taking place in the local and global scientific communities.

Acknowledgments I thank all the native and non-native English speaking scientists, editors, and colleagues in general who shared with me personal experiences and perspectives on the topic of this article. I am particularly thankful to Jorge Crisci, Evan Schwindt, Peter Feinsinger, Mario Bunge, Rafael González del Solar, Claudio De Francesco, Sergio Salazar-Vallejo, Miguel Clavero, and Bo Söderström, whose wise criticism and invaluable suggestions and opinion helped me to organize my thoughts. I also thank SSIS for the motivating exchange of ideas and to CONICET (PIP 190) and ANPCyTFONCyT (PICT $\mathrm{N}^{\circ} 2206$ ) for supporting my work. 


\section{REFERENCES}

Agudelo, J.H. 2010. Publicar en Ingles. Revista Colombiana de Ciencias Pecuarias 24: 1.

Amonn, U. 2001. The dominance of English as a language of science: Effects on other languages and language communities. New York: Mouton the Gruyter.

Bergstrom, C.T., and T.C. Bergstrom. 2006. The economics of ecology journals. Frontiers in Ecology and Environments 4: 488-495.

Clavero, M. 2010a. "Awkward wording. Rephrase": Linguistic injustice in ecological journals. Trends in Ecology \& Evolution 25: 552-553.

Clavero, M. 2010b. Unfortunately, linguistic injustice matters. Trends in Ecology \& Evolution 26: 156-157.

Gannon, F. 2008. Language barriers. European Molecular Biology Organization Reports 9: 207.

Garfield, E. 1962-1973. Essays of an information scientist, vol. 1, 19-20. Philadelphia: ISI Press.

Guariguata, M.R., D. Sheil, and D. Murdiyarso. 2010. 'Linguistic injustice' is not black and white. Trends in Ecology \& Evolution 26: $58-59$.

Halliday, E. 2009. Knowledge is power: In a world shaped by science, what obligation do scientists have to the public? Ethics in Science and Environmental Politics 9: 25-28.
La Madeleine, B.L. 2007. Lost in translation. Nature 445: 454-455.

Meneghini, R., and A.L. Packer. 2007. Is there science beyond English? Initiatives to increase the quality and visibility of nonEnglish publications might help to break down language barriers in scientific communication. European Molecular Biology Organization Reports 8: 112-116.

Montgomery, S. 2004. Of towers, walls, and fields: Perspectives on language in science. Science 303: 1333-1335.

Rotblat, J. 1999. A hippocratic oath for scientists. Science 286: 1475.

Tardy, C. 2004. The role of English in scientific communication: Lingua franca or Tyrannosaurus rex? Journal of English for Academic Purposes 3: 247-269.

Winston, R. 2010. Bad ideas? An arresting history of our inventions, 432. London: Bantam Books.

\section{Alejandro Bortolus $(\bowtie)$}

Address: Grupo de Ecología en Ambientes Costeros, CENPATCONICET, Bvd. Brown 2915, U9120ACD Puerto Madryn, Chubut, Argentina.

e-mail: bortolus@cenpat.edu.ar 